\title{
Exemplar Parents' Practices of Engagement with Their Children's Learning in Finland and Portugal: A Multiple-Case Study
}

\author{
Cristiana Levinthal $\mathbb{D}^{1},{ }^{1}$ Elina Kuusisto $\mathbb{D}^{2},{ }^{2}$ and Kirsi Tirri ${ }^{1}{ }^{1}$ \\ ${ }^{1}$ Faculty of Educational Sciences, University of Helsinki, Helsinki, Finland \\ ${ }^{2}$ Faculty of Education and Culture, Tampere University, Tampere, Finland \\ Correspondence should be addressed to Cristiana Levinthal; cristiana.levinthal@helsinki.fi
}

Received 15 November 2021; Revised 1 January 2022; Accepted 18 January 2022; Published 10 February 2022

Academic Editor: Zhonggen yu

Copyright ( $) 2022$ Cristiana Levinthal et al. This is an open access article distributed under the Creative Commons Attribution License, which permits unrestricted use, distribution, and reproduction in any medium, provided the original work is properly cited.

\begin{abstract}
Parental engagement is a central aspect of children's holistic education, i.e., schooling-related and nonschooling-related learning. Parents' role in supporting such integrative learning is increasingly necessary to develop students' social, emotional, and intellectual skills. Nonetheless, it remains unclear which parental practices support holistic learning. The purpose of this qualitative multiple-case study was to identify and describe the current practices of engagement with learning of four exemplar parents in Finland $(N=2)$ and Portugal $(N=2)$. These four parents of primary-school-age children were individually interviewed, and abductive content analysis was performed to analyze their narratives. Our results evidence four patterns of exemplar practices: showing active interest in the child, supporting autonomy, building a partnership with the teacher and the school, and visiting the child's school. The study concludes that even though exemplar parents use a variety of specific engagement practices, they support holistic learning through their ownership of action in such interactions, clear awareness about their parental role, and consistency in their intentions. Exemplar parental engagement within different cultural contexts was discussed. Recommendations for teachers' pedagogy are presented regarding the benefits of digital communication, goal-oriented invitations to school, and promotion of family time in the home for enhancing children's holistic learning.
\end{abstract}

\section{Introduction}

The need for parental engagement grows as school curricula shift to developing the whole person instead of intellectual skills alone [1-3]. Parent-teacher partnerships play an important role in supporting parental engagement with learning, through effective communication, invitations for engagement, and encouragement of parents' ownership of action $[4,5]$. However, parents' engagement practices with their children's holistic learning may vary widely, as studies show that most teachers worldwide lack formal education on how to engage parents [6-8].

Our aim in this study was to identify and describe current practices of parental engagement with children's learning, used by parents from Finland and Portugal. Finland possesses a renowned and successful educational system [9]. Yet, studies on the topic of parental engagement are still scarce and focus on the teachers instead of the parents [6-8]. In Portugal, studies tend to focus on parental involvement in school-related or schooling-related matters, such as homework support, and to conceptualize learning as students' school achievement [10]. Our study aims to narrow the gap of studies on parental practices of engagement with children's holistic learning, in the home and at the school, i.e., with schooling-related and nonschooling-related learning. Large-scale reports by OECD support the reconceptualization of both parental engagement and learning. The reports highlight the impact of parent-child day-today conversations on children's learning outcomes [3] and investigate children's success in learning from a holistic point of view, including their social and emotional skills, and their family context in more detail [11]. In the following, we describe and analyze the parental engagement practices of four Finnish and Portuguese parents who engage with their 
children's holistic learning in an exemplar manner. In addition, this study responds to a lack of research on the topic of parental engagement in European contexts, in comparison to American contexts [2], and to the need of information regarding parents', rather than teachers' or schools' perspectives [5-7].

\section{Theoretical Background}

2.1. Exemplar Parental Engagement with Learning. This article is a product of a larger study that explores parental engagement with learning and growth mindset among teachers, students, and parents. In this article, exemplar parents were defined by three criteria: they were parents who evidenced an authoritative parenting style while engaging with various spheres of their children's learning $[4,12,13]$, they demonstrated a growth mindset in relation to their children's learning $[12,14,15]$, and they established an effective partnership with their children's teachers [5]. All parents may face challenges in the complex task of raising and educating their children. By highlighting exemplary cases, our intention is to assist in illuminating best practices of parental engagement, by providing description and analysis of their behavior and situating them in specific social and cultural contexts [16]. These three features of exemplar parenting and engagement with learning-authoritative parenting, growth mindset, and effective parent-teacher partnership-are explained in the following sections.

\subsubsection{Authoritative Parenting and Engagement with} Learning. Although there is no perfect model of parenting that will fit every family's profile or situation, the literature consistently points to an authoritative parenting style as an exemplary set of attitudes and practices that strongly benefit learning and achievement $[4,17]$. An authoritative parent can be defined as someone who offers a balance between control and demandingness, on the one hand, and warmth and receptiveness, on the other [13].

Traditionally, home-based parental involvement tends to focus on activities such as homework support (e.g. [18]), while school-based involvement often concentrates on parents' attendance at parental programs at the children's schools [17, 19]. Authoritative parenting style provides a strong basis for successful parental engagement with both school- and home-based learning beyond the schooling matters [4], i.e., with holistic learning. Authoritative parents are aware of the reality of their children's lives and implement actions that guide their children to grow progressively into independent persons $[4,13]$. Although the terms authoritative parenting and parental engagement with learning are not interchangeable, the former establishes the parameters for the latter to develop, and both nourish each other [4]. Authoritative parents engage with their children's holistic learning not because of external requirements or demands, but out of a genuine inner desire.

This means that being truly engaged requires a greater commitment and a greater ownership of action from parents when compared to simple participation. In this form of parental engagement, children's learning is always the key focus and motive of interactions. Here, the concept of learning is grounded in experiencing rather than in studying, rooted in the home rather than the school, and fostered by the agency of parents rather than primarily by the agency of teachers $[2,20]$. Such engagement emphasizes all contexts and contents of children's learning. Engaged parents are involved in schooling matters, but, overall, they are interested in their children's holistic learning and development, of which schooling is a part. Exemplar parents do engage with their children's learning on the basis of information received from the school, but their actions are mostly motivated by their own beliefs, aspirations, and intentions to influence and by their perceptions of their own role as parents $[5,20]$.

A review by Goodall [4] on authoritative parenting illustrates how these exemplar parents build close relationships with their children, where schooling is one more way to get to know them and support their growth. These parents take into account their children's individuality and interests from a young age, know their children's abilities, and adjust their demands accordingly [4, 13]. Their engagement is manifested in simple everyday activities with their children. For example, when children are small, they read to them, or with them, or take them to the library; they sing nursery rhymes, draw and paint together, and they may invite their children's friends over to play [21]. These parents' engagement reflects high levels of agency [22], as they communicate clearly with their children and explain the reasons behind their actions [4]. They build a positive and structured home learning environment, for example, by ensuring that their children have a suitable space to read and complete schoolwork [21]. These parents keep themselves informed about their children's coursework from primary through to secondary school $[4,12,23]$. They hold clear and high aspirations for their children and show active interest in their learning and schooling by, for example, attending parentteacher meetings and helping with homework without being overly critical [4]. They monitor their children's school progress, and they are aware of their children's after-school activities $[4,17]$. They value their children's personal autonomy and own aspirations, advise them about schoolrelated decision-making, and encourage them to think critically by developing their own opinions and decisions $[3,24]$. They instill values [25] and aspirations in their children, communicating the importance of education, engaging in discussions and regular dialogues at home, and mobilizing their own practical knowledge to relate children's academic learning to everyday tasks [3, 4]. Overall, these parents are consistent in their parent-child interactions, and they encourage children's autonomy and sense of competence $[4,13]$.

Studies have been consistent in relating such a parental profile to best practices of engagement with learning. For instance, home-based parental engagement solely focused on homework help is likely to negatively affect children's learning and emotions, if they feel overly pressured [25]. On the other hand, research evidence that the most effective 
parenting style in homework help is marked by high levels of warmth and low levels of behavioral control [18].

2.1.2. Parental Growth Mindset. Another parental feature that has been recently related to exemplary practices of parental engagement with holistic learning is parents' growth mindset $[12,26,27]$. A growth mindset, in short, can be defined as a set of incremental implicit beliefs about one's own ability to develop certain human qualities, such as intelligence, through learning experiences [14]. This set of implicit beliefs affect individuals' motivations when engaging in interaction with other people and tasks of different difficulty levels [28]. For example, a growth-mindset person will exhibit effort and persistence when performing challenging tasks and strive to learn from mistakes, whereas a fixed-mindset person will tend to avoid challenges or errors, striving to maintain current performance levels [28]. Research demonstrates that certain mindset-related parental behaviors are highly connected to their children's own growth mindset development [14].

A key illustration of this is the parental encouragement for children to interpret failure as learning-enhancing [14]. According to Haimovitz and Dweck [14], parents who view failure as debilitating react to their children's mistakes in a performance-oriented manner, such as pitying them, doubting their ability, or comforting them for their lack of ability. Conversely, parents who view failure as enhancing react in a learning-oriented manner, by praising their effort, going through the learning process, and discussing how their children can learn from the experience and improve in the future [14].

Justice and colleagues [26] connected similar parental beliefs and actions to parental engagement practices. They discovered that parents who displayed a belief that effort leads to learning, reported higher levels of parental time investment and engagement with their children in family learning activities, such as telling or reading stories. Another study [27] suggested that the more parents believed that abilities were fixed, the less frequently they would engage with their children's learning and less likely they were to support autonomy and mastery-oriented behaviors in their children.

Consistent with this, the authors of the present study [12] recently examined parental views and practices of engagement in the home and the manifestation of the mindset underlying their engagement. Parents' growth mindset was manifested by encouraging effort, persistence, and practice, approaching difficulties as a natural part of learning, suggesting strategies to overcome those difficulties, encouraging their children to seek challenges and learning situations, advising them to ask questions when in doubt, considering their children's learning context and emotions, and by giving process-focused praise rather than person-focused praise. In addition, parents who engaged with holistic learning would, for example, show interest in their children, encourage their autonomy, provide new learning opportunities, supervise homework according to their children's needs, and keep themselves informed about their children's schooling [12].
2.1.3. Effective Parent-Teacher Partnerships. To keep themselves informed about their children's schooling, parents maintain channels of communication with the teachers and school [29]. Thus, parent-teacher partnerships are one central dimension of parental engagement with learning $[2,5]$. An effective partnership benefits both parents and teachers, as it is grounded in shared agency, mutual respect and legitimation of each other's authority and expertise about learning $[2,22,30]$. Parents and teachers are open to each other's opinions and share a genuine concern not only for the children's schooling but also for all other life contexts that are relevant to the children's learning and growth $[2,22]$. Because teachers recognize the importance of parents' agency, they value the home learning environment and influence parental engagement accordingly [2, 22].

In concordance with this, studies on best practices of engagement have emphasized partnerships with parents as the most powerful factor for lasting and effective changes in learning. These studies have evidenced that mutual trust allows both positive and difficult messages to be exchanged transparently between parents and teachers [31]. Therefore, regular communication is an essential aspect of parentteacher partnerships, which also allows parents and teachers to share their expectations about each other's roles $[5,30]$.

Parents' role construction is important because it has a significant impact on parental engagement with learning. This construction occurs through interaction between parents' beliefs about how children develop and should be raised, and parents' experiences with individuals and groups related to schooling, especially teachers $[5,32]$. Parental role construction is, therefore, defined as "a sense of personal or shared responsibility for the child's educational outcomes, and concurrent beliefs about whether one should be engaged in supporting the child's learning and school success" ([5], p. 107). In other words, parents engage in tasks in which they believe is part of their parental role. The parent-teacher partnership is relevant in this context because teachers' invitations have proven to be the most relevant factor for parents' role construction and practices of involvement with learning $[5,32]$.

The format of teachers' invitations and encouragement to engagement may vary from individual requests to more general calls, such as homework help at home or a school event [5]. Parental homework help has been one of the most commonsense strategies of parental engagement for decades [29], but this is slowly changing as schools advance to develop holistic learning curricula and both parents' and teachers' roles are reconceptualized and adjusted [33]. For example, in a study on homework and home-school relationships in Switzerland, researchers found that a progressive decrease in homework caused parental feelings of loss of control over and loss of connection to their children's school learning [34]. This scenario is an example of the need for teachers to adapt their communication in order to help parents feel informed and included and, ultimately, to support children's holistic learning.

One way parent-teacher communication has been evolving by the utilization of online tools. An example of this is the Finnish educational context, where online platforms 
are widely used to exchange messages on study-related matters, behavioral issues, and for parents to receive up-todate information on their children [35]. A recent study conducted by the authors of the present article among a group of Finnish parents [23] suggested that these parents valued being informed about their children's learning processes and that this would happen mostly through the online platform. The parents reported a sort of need to be present at the school building, referring they trusted the teachers' competence and felt engaged with their children's home- and school-related learning [23].

\subsection{The Context of Parental Engagement in Finland and} Portugal. We decided to explore the contexts of Finland and Portugal because both have recently introduced important curriculum and policy reforms with holistic pedagogical aims $[1,36]$. As a result, the two countries represent promising environments for investigating parental engagement. The two nations also display other important similarities. For instance, both are members of the European Union (EU) and the Organization for Economic Cooperation and Development (OECD). At the same time, their cultural and educational background are sufficiently different to make such a comparison fruitful.

Education has always been a central value in Finnish society, and teaching has long been a respected and appreciated profession [9]. This is due, in part, to factors such as moral values and a reliable welfare system, high-quality teacher education, and a history of pioneering educational reforms [23, 37]. In Finland, teachers are regarded as ethical and autonomous professionals, who have the expertise and authority to make decisions on how to implement the national curriculum guidelines [9]. In Finland's official curriculum documents [40], parents are consistently mentioned as guardians. Generally, the references concern parents' right to be kept abreast of and included in a timely fashion in relevant decisions on their children's schooling, such as in individual learning plans or the amount of support for special needs students [36]. The same document states that home-school cooperation supports teachers' work, enables the work of parental associations, and promotes socialization among parents [36].

Home-school relationships are, therefore, based on trust and mutual respect $[23,37]$. According to Böök and PeräläLittunen [38], Finnish parents draw a clear distinction between school and home responsibilities, and between parents' and teachers' role, recognizing teachers as the main figures of authority in school-related matters. Our recent study with Finnish parents confirms such trust in the professionalism of teachers, reporting regular online communication and collaborative, goal-oriented, face-to-face meetings with the teachers [23]. However, early career teachers report lack of formal knowledge and confidence to engage parents with learning [6] and even experienced school principals state that cooperating with, for example, multicultural families, is challenging [39].

In Portugal, the teaching profession has endured a history of obstacles and control that started to improve mainly after Portugal became a democracy, in 1974 [40]. Influenced by EU policies, teacher education became uniformly standardized, in the early 2000s [40], which earned the profession more respect and attractiveness. However, according to recent reports [41], the Portuguese teachers are the most stressed amongst the EU countries, due to their lack of autonomy in decision-making and daily administrative demands. As for parents, their role has traditionally been one of homework support [42]. Nevertheless, a Portuguese study revealed that parents who did not assist their children with homework reported lower stress levels, and that parents considered homework a source of family conflict and of inhibition of family time [43].

The 2018 policy reform in Portugal, partially inspired by the Nordic educational models $[1,40]$, marked a shift from a more passive parental role to presenting official guiding principles for parental involvement [44]. Parents started to be acknowledged as active stakeholders in their children's learning, home-school dialogue was encouraged, and the role of parents has been elevated. Nevertheless, our recent study with Portuguese parents still indicated a more traditional profile of engagement, dependent on the school's space and initiatives, grounded in face-to-face interaction and triggered by the emergence of a problem or other more immediate needs [23]. In accordance with this, evaluation of these processes of change in Portugal have concluded that it is unrealistic to expect practical improvements in education without assigning priority to teacher-education needs [40] and the enhancement of teachers' working conditions [45]. This means that new ideals of teacherparent partnerships, parental engagement, and holistic learning, among other aims, currently encounter deep structural obstacles of implementation in Portuguese schools.

In sum, Finland and Portugal count on a set of ambitious but challenging educational goals, different contextual challenges, and low scientific knowledge on parental engagement with holistic learning. This, paired with a framework of exemplar parenting, allows for a detailed study of best practices of engagement in the two countries. The aim of this multiple-case study was to identify, describe, and analyze the current practices of parental engagement of exemplar parents in Finland and Portugal. Thus, we address the following question in this study: How do exemplar parents engage with their children's learning in Finland and in Portugal?

In educational research, case studies serve as a tool that elevates the understanding of context, individuals, and communities [16]. Bringing forward exemplar cases in educational research assists in illuminating teachers' and schools' best practices and allows for an in-depth analysis of complex processes, while situating them in specific social and cultural contexts [16].

\section{Material and Methods}

3.1. Participants, Instruments, and Procedure. This is the third and last study of a series of exploratory studies about Finnish and Portuguese parental engagement perspectives 
TABle 1: Parents' background information.

\begin{tabular}{lcccc}
\hline & Timo & Satu & Sofia & Paulo \\
\hline Nationality & Finnish & Finnish & Portuguese & Portuguese \\
Location & Helsinki & Helsinki & Lisbon \\
Gender & Male & Female & Male \\
Age & 43 & 44 & 44 & 40 \\
Education & University & University & University \\
Occupation & Journalist & Entrepreneur-communication & Human resources & Information Technology \\
Child & buho & manager & Programmer \\
Child's age & 9 & 10 & 7 & Bruno \\
Child's school & 3 & 4 & 2 & 8 \\
year & Male & Male & Female & 2 \\
Child's gender & One older brother & No siblings & One older sister & One younger sister \\
Siblings & challenges & Motor skills challenges & No specific challenges & Behavioral challenges \\
Challenges & & & & Male \\
\hline
\end{tabular}

and practices, and 19 parents were interviewed $[12,23]$. The participants were parents of first- to sixth-grade students from Helsinki and Lisbon, the capital cities of Finland and Portugal, respectively. Thematic interviews were conducted with each parent on the topics of parental engagement with their children's learning at home and at school, their children's challenges and successes in learning, and parentteacher partnerships. The first study explored parental engagement in the home learning environment and the parents' growth mindset [12]. The second study analyzed parents' perspectives on the role of the teacher in supporting parental engagement in the school and parent-teacher partnerships [23]. As exemplar parents, the present study selected four of those parents, two Finnish and two Portuguese, whose narratives evidenced the following:

(i) an authoritative parenting style in engagement with their children's holistic learning: 60 to 90 percent of their engagement-related statements had been characterized as engagement with the holistic development [12].

(ii) a growth mindset about their children's learning: 90 percent or more of their mindset-related statements had been characterized as growth mindset [12]

(iii) an effective partnership with the child's teacher: they had reported positive parent-teacher collaboration regarding communication, teachers' professionalism, and teachers' invitations for active participation [23]

Moreover, the selected individuals were reflective in sharing their perspectives, therefore providing rich narratives. These cases constitute examples of different exemplar parents' practices of engagement with their children's holistic learning. Table 1 provides detailed background information about each parent and their children (pseudonyms are used).

The interviews were conducted face-to-face with the Finnish parents and via the videocall software Zoom with the Portuguese parents. The participants consented to the interviews and its use for research purposes. They were informed about the interview's theme and, to reduce social desirability in narratives, parents were informed that there were no right and wrong answers and that the interviews would be later anonymized. .

We used a semi-structured interview protocol to ensure consistency between interviews [46]. The opening question was, "please, tell me what, in your opinion, makes for a successful teacher-parent partnership?" The narratives were followed by clarifying questions from the researcher, who would lead the conversation to the subsequent topic of discussion in a natural manner. Examples of such questions included, "what does parental engagement with learning mean from your point of view?," "how can parents engage with learning at home?," and "how can parents engage with learning at the school?" The sequence of questions varied from one interview to the next to promote the spontaneous flow of conversation.

Each interview lasted approximately one hour. All interviews were conducted by the same researcher in English with the Finnish participants and in Portuguese with the Portuguese.

3.2. Data Analysis. To identify and describe the parents' engagement practices, this study focused solely on concrete actions, whilst the previous studies [12,23] analyzed parents' actions, implicit beliefs, attitudes, and more abstract explanations.

The first author conducted abductive content analysis for a more complete understanding of the data [47]. Thus, the analysis combined both inductive and deductive approaches. First, every parental action described by a parent as an intentional engagement with their children's learning was selected as an independent unit of analysis and coded. Second, these actions were categorized utilizing theoretical perspectives drawn from the literature $[2,4,12,22,23]$. Moving back and forth between concepts and data, subcategories were then created as a means of integrating actions and concepts [47].

The unit of analysis constituted a meaningful statement that answered the research question, varying from short 
TABLE 2: Frequencies $(f)$ of categories and subcategories of exemplar parents' engagement practices.

\begin{tabular}{|c|c|c|c|c|c|c|}
\hline \multirow{2}{*}{ Categories and subcategories } & \multicolumn{6}{|c|}{ Frequency of Statements } \\
\hline & Timo, FIN $f$ & Satu, FIN $f$ & Sofia, PT $f$ & Paulo, PT $f$ & $\mathrm{FIN} / \mathrm{PT} f$ & Total $f$ \\
\hline Showing Active Interest in the Child & 10 & 6 & 14 & 15 & \multirow{4}{*}{$16 / 29$} & \multirow{4}{*}{45} \\
\hline Interest in Schooling Matters & 3 & 2 & 10 & 4 & & \\
\hline Interest in Well-being & 4 & 1 & 3 & 7 & & \\
\hline Interest in Hobbies & 3 & 3 & 1 & 4 & & \\
\hline Supporting Autonomy & 6 & 10 & 4 & 7 & \multirow{3}{*}{$16 / 11$} & \multirow{3}{*}{27} \\
\hline Personal Autonomy & 6 & 7 & 3 & 6 & & \\
\hline Social Autonomy & 0 & 3 & 1 & 1 & & \\
\hline Building a Partnership with the Child's Teacher and School & 2 & 10 & 5 & 2 & \multirow{4}{*}{$12 / 7$} & \multirow{4}{*}{19} \\
\hline Responsiveness to the Teacher & 0 & 5 & 2 & 1 & & \\
\hline Digital Communication & 1 & 3 & 2 & 1 & & \\
\hline Face-to-face Collaboration & 1 & 2 & 1 & 0 & & \\
\hline Visiting the Child's School & 1 & 1 & 3 & 5 & \multirow{3}{*}{$2 / 8$} & \multirow{3}{*}{10} \\
\hline General Participation & 0 & 1 & 1 & 5 & & \\
\hline Individualized Participation & 1 & 0 & 2 & 0 & & \\
\hline Total statements & 19 & 27 & 26 & 29 & $46 / 55$ & 101 \\
\hline
\end{tabular}

clauses to entire paragraphs of spoken text [48]. Coding exclusiveness was applied, meaning that each statement was assigned just one code.

The analysis was performed using Atlas.ti 8 software. Altogether, 105 statements related to exemplar parents' engagement practices were identified, coded, and categorized [48]. To increase the reliability of the analysis, at the end of the process, the first and second author jointly revised each category, subcategory, and respective code. Finally, the analysis process generated 101 statements, categorized into four main categories and 10 subcategories (Table 2).

\section{Results}

We present four cases of parents, two from Portugal and two from Finland, whose narratives conveyed exemplary practices of engagement with their children's learning. The results are grouped under four main categories that correspond to the parents' practices of engagement with learning. The categories were (1) Showing Active Interest in the Child, (2) Supporting Autonomy, (3) Building a Partnership with the Child's Teacher and School, and (4) Visiting the Child's School. Table 2 shows the frequencies of these categories and subcategories in our data, summarizing the results by individual, country, and total.

The purpose of this study was to identify and describe practical examples of exemplar parents' engagement with their children's learning. Table 2 demonstrates that, even though these exemplar parents engaged with their children's learning in similar forms, the actual focus of their practices varied considerably.

4.1. Showing Active Interest in the Child. Showing active interest in the child was the strongest pattern in all four parents' narratives. Demonstrating interest and genuinely engaging with their children's learning, independently of the nature of that learning, seemed to be perceived as a core feature of being engaged. This was more frequently mentioned by the Portuguese exemplar parents $(f$ Port $=29)$ than by their Finnish counterparts $(f$ Finn $=16)$. Within this main category, parental engagement related to interest in schooling matters, interest in well-being, and interest in hobbies. In the following example from Portugal, a mother explains her style of support in complementing school academic teaching and making sure the child acquires content knowledge. The following statement from the interview with the mother demonstrates the importance she places in the school tests and how she thinks it is her role, as a parent, to support that learning as "a second teacher," even though she trusts the teacher's competence. The mother mentions, as well, that she is not frequently able to give this kind of support to the younger daughter, because of new pandemicrelated demands.

My [older] daughter would leave school and would have a second teacher at home, because I would give her new assignments, specially prior to school tests. So, we would study, both of us together. I would make questions and she would answer. [...] With the younger it does not happen so much [...]. The routine, the day-to-day life, changed [due to the pandemic]. But every time it is possible, prior to the tests, there is this involvement, this proximity. I have always been involved, I have always been there, as a second teacher. [...] I think this role is very well performed by my daughters' teachers, but at least I give them this back-up support. (Sofia, PT).

Sofia's interview highlights her strong commitment to her child's school success. Other practices of showing interest in the child's schooling, shared by the exemplar parents, were asking the child if they had completed their homework, keeping the child company while doing homework, learning how to use new technology to support the child's schooling, or explaining school content whenever necessary.

All parents exhibited interest in the child's well-being. These seemed to be important practices of engagement with learning for our exemplar parents because they viewed that 
setting limits and rules and ensuring the child felt acknowledged were an intrinsic part of their parental role. In the following interview excerpt, the Finnish father, Timo, describes how he normally reacts with enthusiasm when his children recall an important achievement of theirs at home.

[When the kids achieve something] we cheer them, throw a high-five in the air [...], we might ask them what was the best part, or what was difficult, or why did you succeed - let them relive their excitement with us and tell us. It can be a school thing, or a hobby thing, but we can see their eyes glowing [...], and we want to be there, listen to them and enjoy it with them. I think it is important to listen and enjoy the excitement [...].(Timo, FIN)

Timo's narrative clearly indicates his interest in his children's well-being and the intentionality of his approach, regardless of the nature of their learning, as he emphasizes the children's needs and the impact of his actions on them. In a similar manner, interest in the child's well-being was also frequently mentioned by the Portuguese father. This showed that, in our sample, fathers more than mothers perceived as parental engagement tasks such as ensuring the child was well-fed and rested for the school day, asking about school routine and monitoring access to smartphones or social media as parental engagement.

Our exemplar parents' interest in their children also appeared in the form of interest in hobbies and included a variety of leisure-time and creativity-related parental actions. In the case of Finns, hobby had a strong connection with supporting the child in experiencing own abilities, encouraging interests, and exploring individuality, for example, by making musical instruments available at home, camping, watching YouTube videos together, or taking the child to museum exhibitions. For the Portuguese, these activities conveyed the core idea of spending quality time together, such as reading stories and books to the child, allocating daily time to play, or providing opportunities for the child to experience nature.

Overall, these parents mentioned interest in their children as an essential part of their parental engagement with learning-a facet of parenting they appeared to regard as both a parental duty and a source of satisfaction in relation to their children. Referring to such practices as parental engagement with learning evidences, once more, how the exemplar parents perceive learning as holistic and the importance of their ownership of action in participating in their children's lives.

4.2. Supporting Autonomy. Another key pattern found amongst our exemplar parents was their support for their children's autonomy. For all parents, this was a prominent practice of engagement with learning, but this was especially the case for the Finns $(f$ Finn $=16$; fPort $=11)$. These parents engaged in supporting their children's autonomy both at a personal and social level, even though the former was more frequently mentioned by all. The interview of the Finnish mother was a very good example of the authoritative parenting style. She established parent-child dialogues that aimed for their children's growth and independence, while also providing support and warmth.

Satu proved herself to be closely involved in her son's schooling. Lauri, her son, had exhibited some difficulties in fine-motor skills since pre-school. These difficulties were primarily manifested in challenges to draw or write. Satu had been extremely active in supporting her child at home, which had clearly helped Lauri succeed throughout primary school. In the following situation, she shared how she provided Lauri with concrete strategies for overcoming such difficulties and talked to him about the importance of exploring learning choices and preferences in life.

I knew that he had to get the experience that he can do it; this was what I was thinking about. He took a sheet, he wrote and he was completely dissatisfied; he rubbed it off, the sheet was in wrinkles, and then he cried. [...] I constantly repeated "you don't have to do it neatly; you just have to do it because you train; that's it, just do it somehow, because you exercise, to practice. It's okay, you are learning." [...] This was very important to me. I just wanted him to understand that there are some things you just have to do, and, yes, you have the right to do them at the least approvable level, but still, you have to do them, at some level. [...] It's very important that he can figure out what he really likes, what brings satisfaction and joy of doing, and what [are the things] that he just has to do. [...] I would like to teach him the skill of prioritizing what is really important for him and [knowing] what is less important. (Satu, FIN)

In these statements, Satu describes that the intention of her schooling-related support, on the one hand, is to provide her child with the experience of success and, on the other hand, to teach him the importance of being persistent and committed to a task, even though it can be frustrating and not enjoyable. Here, the task was a means used by Satu to instill autonomy and values, instead of a goal in itself. A similar position was also seen in the Finnish father's narratives. For Timo, the development of his sons' personal autonomy was a central goal in his specific parenting role, although he used a different setting as a learning context. Timo took great pride and joy in describing his children's ability to fish or pitch a tent by themselves at young age and the way he had promoted his children's autonomy in the nature. He described the importance that he and his wife placed on allowing the children to "explore the world around them," rather than simply remaining at home after school, and their complete trust in their children's ability to cope and learn from such experiences.

For Sofia, the Portuguese mother, supporting her daughter's personal autonomy was related to explaining that mistakes were acceptable and also to encourage her to be persistent in the face of learning difficulties. Most of Paulo's narratives focused on supporting his son's personal autonomy by helping him manage negative emotions and frustrations and encouraging him to make difficult decisions. Concerning the latter, the following statement from 
Paulo exemplifies how he supported personal autonomy by attempting to equip his child with tools to promote emotional intelligence:

He has some difficulties in making decisions when he has two or three options and they're all good. He blocks out, sometimes gets stressed. [...] I think that where my engagement makes the most impact is in helping him to get out of this indecision without having to experience unjustifiable levels of stress. [...] I usually say to him [.. .] that if he is not getting it at that moment, he might understand it later. [...] I try to explain to him that he is not incapable, he just doesn't understand it, and the more he doesn't understand it, the more he gets irritated, and the more irritated, the less ability he has [to understand it]. (Paulo, PT)

The main difference between the Finnish and the Portuguese parents' discourses was that the Finns seemed more actively engaged in taking advantage of challenging situations to enhance learning, while the Portuguese would focus on comforting and providing tools to move on from the difficulties. Therefore, the growth mindset of the Finnish parents was, in the described situations, more evident.

In turn, supporting autonomy at the social level, for the Finnish mother, included, explaining how to interpret and act in social situations and explaining that attending school is a societal rule, not an individual choice. For the Portuguese parents, this showed in their discourses as encouraging the child to ask for others' help and make questions, and in passing on social principles, rules and limits to the child. All parents revealed sensitivity to adapt their approach to their children's age and own personality while supporting social autonomy.

4.3. Building a Partnership with the Child's Teachers and Schools. Another important aspect of these exemplar parents' patterns of parental engagement was their intent to build a partnership with the child's teachers and school, even though this was more frequently mentioned by the Finns than by the Portuguese $(f$ Finn $=12$; $f$ Port $=7$ ). The parents built these partnerships by being responsive to the teachers, communicating digitally with the teacher, and engaging in face-to-face collaboration.

In terms of responsiveness to teachers' recommendations or feedback, the parents indicated practices such as interacting with the child in a manner coherent with the teacher's approach, rewarding the child for the teacher's positive feedback, or creating a book-reading activity at home to be presented in the classroom. Satu was the parent that most frequently mentioned her partnership with the teacher, and her responsiveness to the teachers' approach. Lauri's motor skills difficulties were at the base of such close and consistent communication, as both mother and teacher shared the responsibility of supporting Lauri's learning.

Digital communication supported Satu's partnership with the teacher and was also mentioned by Timo, the Finnish father. It occurred both at the parents' initiative, for instance, by sending a message to the teacher to clarify a question about school content learning, or at the initiative of the teacher or the school, in which case the parents would read the messages and respond accordingly. For the Finns, almost instant communication was more easily accessible through the Wilma online platform, a parent-teacher communication platform used nationally. As they lacked a specific online platform for maintaining regular communication with the teacher, the Portuguese parents sporadically contacted the teacher from home by phone or e-mail, mainly to request assistance or information to support their children's homework.

Satu, the Finnish mother, viewed digital communication as a means of relevant and regular exchange of information. She consistently demonstrated clear respect for her child's teachers and placed great value on her partnership with them. In the excerpts below, she explains that regularly reading online messages from the teacher and the school is an important feature of engaging with learning. The statements are also an example of how digital communication may prompt parents' responsiveness to initiatives from the school or teacher:

I appreciate it [Wilma platform] very much because there I see the whole picture. Because we have these color marks there [...] and then I see the whole statistics visualized, what was going on, and how he was doing. [...] And this is good, this is what I appreciate in this partnership. I am always up to date on what is happening at school. It feels very safe, it feels very secure. [...] I feel it's much more convenient when I have this constant, on a daily or on a weekly basis, information on how my child is doing. [...] I can say that it's a very good way to inform parents, because we get a lot of information, but not too much. (Satu, FIN)

On the topic face-to-face collaboration, the Finnish parents produced more statements than did their Portuguese counterparts. For instance, they mentioned meeting with the school's principal to take decisions on the future of their child's schooling and meeting with the teacher to reflect together on their child's schooling progress. The only Portuguese mention of this practice referred to meeting with the teacher to support the child's transition from kindergarten to first grade and reflected a specific situation that required special attention from the school. The face-to-face collaboration with the teacher was cited by Finnish parents as a standard national procedure that occurred at specific times of the academic year in order to discuss the children's progress in learning.

In general, within our four exemplar parents' experiences, the partnership with the teacher or the school had a more pre-defined and predictable pace in Finland, with parents knowing when, why, and how they would collaborate. The Portuguese parents' narratives evidenced a more spontaneous, less structured and less goal-oriented relationship with the teacher and schools, as it would happen mainly in attendance of school events, instead of specific collaboration. This can be explained by the more traditional forms of parental engagement that are promoted by schools 
in Portugal, and also by the fact that the Finnish parents have more time of experience in partnerships, as their children were slightly older than the Portuguese.

4.4. Visiting the Child's School. The fourth and final practice of engagement reported by parents was visiting their children's school. This practice was far more frequently mentioned by the Portuguese exemplar parents ( $f$ Port $=8$; $f$ Finn $=2$ ). Both Finnish parents expressed high levels of trust in the school and its teachers and preferred to communicate at a distance while also managing their own work schedules and other personal projects. In terms of general participation, they mentioned attending a large spring event in which the whole school community participated, while, in terms of individualized participation, they mentioned meeting the teacher in a larger group of parents for an annual briefing. They explained that, apart from such scheduled events during the academic year, they were not, and had no intention of being, in the habit of visiting the school more regularly.

In contrast, the Portuguese parents expressed a more frequent presence in their children's schools. Both were accustomed to visiting the school for general or individualized participation. Sofia stressed the importance of parents being sporadically invited as visitors to the school, provided there was a clear pedagogically related goal. For example, she considered it valuable for parents to visit the school to become acquainted with all their children's teachers and the school's spaces. However, Sofia's narrative revealed that it was her partnership with the school as an institution, and her individualized participation, that played a central role in her engagement. In her case, being part of the parents' association and the parents' representative of her daughter's classroom provided her with special opportunities to become integrated into school life and engage in closer dialogues with her daughter's teachers.

In contrast to Sofia, Paulo, the Portuguese father, preferred to practice his parental engagement through various kinds of general participation events at his child's school. He considered these events enjoyable and a means of socializing with the teachers and other families. Paulo listed a number of activities in which he had participated in response to invitations from the teacher or school. For example, he had attended a family day, Christmas parties, end-of-academicyear celebrations, cycling outings with other parents, and classroom book readings with his son. Paulo viewed prioritizing such participation in parental events as a considerable portion of his parental engagement with the teacher and the school. In the following statements, he reports that such engagement practices are moments when he can serve as an example to his children, and, most importantly, positively affect their learning:

Everything that has to do with our children always has to be a priority. I feel that our participation is very, very important for their development. I see it in their reaction, and that's why I'm always a volunteer to participate. [...]And then at the same time it turns out to be an engagement that
I consider educational, in the community, showing children that not only do they work well in groups in the classroom, but we all work well in groups, even when we don't know each other. (Paulo, PT)

Sofia's and Paulo's practices are good examples of how these Portuguese exemplar parents combine teacher or school partnership with physical presence at the school. In contrast, Satu and Timo engage with the school and teachers in a more convenient and sporadic manner. Overall, although these four parents all engaged with their children's holistic learning and with their children's teachers and schools, each of them utilized their own individual resources to produce different practices. While the Finns concentrated on showing interest in their children, supporting their autonomy, and partnering up with the teacher from a distance, the Portuguese were dedicated to showing an active interest in the child and building a partnership with the teachers and schools by being physically present. This difference in practices can be partially explained by the respect and trust Finnish parents, and the whole society, place in the teachers' work. The fact that Finland is a highly digitalized society may as well contribute to parents feeling lower needs to be present in the school. In addition, Finns tend to attribute great value to work-life balance, time for family and for oneself, which may influence the lack of interest in visiting their children's schools without an obvious need. Similarly, teachers may refrain from frequently inviting parents over to the school, which implicitly communicates their expectations of engagement.

Without exception, these parents exhibited their growth mindset when they encouraged their children to be persistent and offered them strategies to overcome difficulties, and such incremental implicit beliefs were embedded in their actions. On the other hand, these exemplar parents, too, experienced less confident moments.

For example, while counting on the teacher's close support, Sofia focused on being present both at home and at the school, managing her daughter Maria's routine and reinforcing her school academic learning at home. However, she also reported struggling to adapt the amount of support she was able to offer Maria during the pandemic and the new home routines. In turn, Paulo strove to engage with his son Bruno both by equipping him with self-knowledge and selfcontrol skills and accepting every invitation for participation from his school. Nonetheless, Paulo also shared that, in order to comprehend Bruno better and to create strategies to help his son, he relied on his own growth and overcoming, as a father and a person.

Timo expended a great deal of energy teaching life skills and responsibility and providing his son Juho and his brother with opportunities for experiencing nature while trusting completely the work of the school and the teachers. However, Timo also reported a sense of guilt over his lack of time and commitment to read online Wilma messages and monitor his sons' schooling more closely. Finally, Satu, who closely monitored her son's education by frequently communicating with the teacher through Wilma and encouraging her child to develop persistence and commitment, also 
struggled. For instance, she had asked herself many times, when Lauri was in first grade, whether she should actually persist with her efforts and whether he would ever develop those fine-motor skills.

\section{Discussion and Conclusion}

This multiple-case study of four exemplar parents from Finland and Portugal reported on best practices of parental engagement with children's holistic learning. We identified and described parental engagement practices and the similarities and differences between Portuguese and Finnish parents. Our findings demonstrated that exemplar parents practice engagement by showing interest in their children, supporting autonomy, building partnerships with teachers and schools, and visiting their children's schools.

Our results are in line with previous research indicating that displaying interest in the child and supporting autonomy are core features of authoritative parenting and serve as the optimal basis for parental engagement with holistic learning [4, 13, 17]. Here, the Finnish and Portuguese parents were extremely similar. However, the content of their discourses revealed the complexity of their motivations to engage $[5,32]$. The mothers' role construction was more connected to schooling-related support, while also embedded in supporting autonomy development and holistic learning. The fathers more frequently mentioned hobbies and leisure activities as parental engagement with learning but also revealed a clear set of expectations for their children's learning and development $[4,13]$. The parents' narratives were congruent to their style of partnership with the teacher and the teachers' invitations, which support previous studies on the importance of the teachers' invitations to parental role construction and engagement $[5,30]$. Our results are in line with previous studies indicating that developing partnerships and inviting parents to school are major motivators of parental involvement [5, 31]. Nevertheless, the frequency with which our parents mentioned this form of engagement varied significantly, signaling fundamental differences right from the start.

Cultural and contextual characteristics may also play a part in how these parents practice their parenting and parental engagement. For example, Portuguese parents tend to engage with learning in a more traditional manner, with assisting in homework or studying often representing a large portion of home-based parental engagement [42]. Finns, on the other hand, display high levels of appreciation for and trust in teachers and the social welfare system in general and thus tend to favor outdoor leisure activities or even supporting homework in a less direct manner, such as being present and available if the child requires support [9, 23, 37].

Technology plays an undeniable role both in today's communication and in Finnish education in general [35]. Although this topic requires further research, it seems likely that Finns currently use the online platform Wilma as the primary form of communication and partnership with teachers and schools. In the case of the Portuguese, their engagement with teachers and schools mostly occurred through face-to-face communication and visiting the school premises. Nevertheless, while Paulo valued all kinds of school activities, Sofia was more focused on participating in the school's decision-making and forming a close relationship with teachers by being active in the Parents' Association. The difference between the Finns and the Portuguese could be explained, among other individual factors, by the parents' cultural background. Time is extremely valued in Finnish culture, where people strive to be efficient and pragmatic. That, together with the fact that Finland is a highly digitalized country, supports effective online communication between home and school and sets the tone for pedagogically related future face-to-face meetings [23]. In the Portuguese culture, by contrast, parental engagement tended to include more regular visits to school. This could be partially explained by teachers' lack of time and their highly stressful work routine [45], which is likely to be an obstacle for discussing and innovating parental engagement practices.

A growth mindset was present in all the parents' narratives in relation to autonomy-supportive goals [27, 28]. The parents were extremely eager to encourage their children to learn and overcome challenges by, for example, offering concrete strategies and encouraging persistence and practice $[12,14,26]$. Nonetheless, here, a slight but interesting difference between the Finnish and Portuguese parents was identified in their practices. While all the parents encouraged their children to overcome challenges, Satu and Timo, the Finnish parents, revealed a special tendency to interpret challenges as life enhancing.

These parents' narratives revealed significant aspects of their individual experiences, parenting styles, mindsets, and role construction in relation to their children's learning. Both the Finnish and Portuguese exemplar parents identified distinct roles for the home and school and seemed to view both as mutually complementary to the children's learning path. However, the Portuguese tended to view the home space and their parental engagement practices as more complementary of the schools' goals, whilst the Finns seemed to place greater emphasis on the primacy of the parental role and engagement and its independence from that of the school. Our exemplar Finnish parents placed great value on schooling, but they tended to see it as the teacher's responsibility and a part of their children's life that supported parallel parenting goals, as suggested by previous research with Finnish parents [38]. Moreover, they expressed clear goals and aspirations for their children as individuals, even at a young age [4]. On the other hand, our exemplar Portuguese parents dedicated themselves to their children's schools and engaged to ensure that their children acquired the necessary content knowledge and to remain up to date with the school's decisions and activities. This may be the most intriguing difference between the Finnish and Portuguese exemplar parents. Even though the Portuguese parents supported their children's autonomy and were interested in their children's well-being and hobbies, the schooling process and the school events seemed to dictate a greater portion of their actions, and they were yet to display specific aspirations or visions for their children's future as individuals. 
The main contribution of this study refers to identifying, describing, and analyzing concrete practices of parental engagement in two contexts of holistic pedagogy Even though we cannot claim which specific practices have greater impact in learning itself, the study provides valuable information for the implementation of parental engagement according to holistic pedagogical aims, offering transferrable insights for parents, teachers, schools, and teacher education. Overall, our findings underline the need for both school-based and home-based parental engagement to be debated, reconceptualized, and agreed upon within school communities.

Invitations for parents to visit school must focus on specific goal-oriented and learning-centered situations, such as introducing the staff or the school space, strengthening the home-school relationship, or directly supporting children's transversal competencies. Ideally, these situations should not overwhelm parents, teachers, or schools, inhibiting the learning that naturally occurs at home and at school. Schools and teachers should educate parents on the importance of home-based engagement with learning and on practical means for putting it into practice. For instance, the school's expectations of parental support for homework tasks should be carefully discussed with parents. In addition, teachers must communicate to parents the value the school places on family time and instruct parents on practices that influence children's holistic learning. Teachers could also explore how parents deal with their children's challenges and failures and influence the shaping of parents' growth mindset about their children's learning by educating parents on how setbacks serve as unique steppingstones for learning and growth. Parents should be informed about the importance of this kind of home-based engagement and how deeply it contributes to the schools' goals of educating creative, curious, and critical citizens. Finally, teachers should take advantage of available online communication tools as a means of engaging in regular communication with parents, keeping them informed, and exchanging feedback in order to develop and strengthen their partnerships. Even though face-to-face collaboration is essential, teachers' investment and training in communication platforms promise to shorten home-school distances to enhance teachers' positive influence on learning.

5.1. Limitations and Future Research. The educational background of the parents interviewed for this study was rather homogeneous, as they had all completed a highereducation degree. Even though our goal was never to generalize the results, it is important to acknowledge that it would have been beneficial to interview exemplar parents with different educational profiles and socioeconomic backgrounds. Furthermore, it is important to note that a different set of interview questions could have produced different findings, as we aimed to explore best practices of engagement and therefore focused on effective practices and successful partnerships. Moreover, this study did not attempt to measure the children's school achievement or their overall holistic learning. Therefore, we relied on parents' narratives of their experiences. Although all such narratives were conveyed openly and consistently, we must acknowledge the possibility that their discourses were tailored to social expectations.

We acknowledge that our findings would present greater validity if means of methodological triangulation had been used in data collection, such as the implementation of questionnaires and/or inclusion or a third researcher in the analysis process. Although we recognize that the results are nongeneralizable, we believe that both general and culturally specific findings shed new light into best practices of parental engagement with holistic learning that can be transferrable to similar contexts, if conditions of implementation are carefully observed. The study's qualitative design provides rich descriptions of the participants' experiences and meaning-making in their own words. Such individualization is one of the most salient advantages of qualitative research [48]. The first author conducted, transcribed, and participated in the analysis of all the interviews, allowing the data to be studied in a comprehensive and reliable manner. Abductive content analysis, in turn, enabled the surface and deeper structures of the parents' narratives to be integrated and their experiences to be positioned within a theoretical framework [47]. Therefore, the methodology supported the study's aim of portraying best practices of exemplary parental engagement and situating them in specific social and cultural contexts [16].

We recommend that future studies on this topic explore more diverse settings, interviewing parents from immigrant backgrounds and various socioeconomic groups. In addition, it would be valuable to investigate teachers' perspectives on the same topics. We encourage the investigation of practices of parental engagement with learning from a holistic standpoint while also measuring the features of children's holistic learning and development, such as intellectual, socioemotional, cultural, technological, entrepreneurial, and analytical factors.

\section{Data Availability}

The raw data supporting the conclusions of this article will be made available by the authors upon request.

\section{Conflicts of Interest}

The authors declare that they have no conflicts of interest.

\section{References}

[1] DGE-Direção-Geral de Ensino, "Perfil dos alunos à saída da escolaridade obrigatória [student profile by the end of compulsory schooling]," 2017, https://dge.mec.pt/sites/default/files/ Curriculo/Projeto_Autonomia_e_Flexibilidade/perfil_dos_alu nos.pdf.

[2] J. Goodall, "Learning-centred parental engagement: Freire reimagined," Educational Review, vol. 70, no. 5, pp. 603-621, 2017.

[3] OECD, Let's Read Them a Story! the Parent Factor in Education, OECD Publishing, Paris, France, 2012. 
[4] J. Goodall, "Parental engagement to support children's learning: a six point model," School Leadership \& Management, vol. 33, no. 2, pp. 133-150, 2013.

[5] K. V. Hoover-Dempsey, J. M. T. Walker, H. M. Sandler et al., "Why do parents become involved? Research findings and implications," The Elementary School Journal, vol. 106, no. 2, pp. 105-130, 2005.

[6] A. Alanko, "Preparing pre-service teachers for home-school cooperation: exploring Finnish teacher education programmes," Journal of Education for Teaching, vol. 44, no. 3, pp. 321-332, 2018.

[7] V. Harju and H. Niemi, "Newly qualified teachers' needs of support for professional competences in four European countries: Finland, the United Kingdom, Portugal, and Belgium," Center for Educational Policy Studies Journal, vol. 6, no. 3, pp. 77-100, 2016.

[8] I. Thompson, M. Willemse, T. Mutton, K. Burn, and E. De Bruïne, "Teacher education and family-school partnerships in different contexts: a cross country analysis of national teacher education frameworks across a range of European countries," Journal of Education for Teaching, vol. 44, no. 3, pp. 258-277, 2018.

[9] R. Jyrhämä and K. Maaranen, "Research orientation in a teacher's work," in Miracle of Education: The Principles and Practices of Teaching and Learning in Finnish Schools (S. 91108), H. Niemi, A. Toom, and A. Kallioniemi, Eds., Sense Publishers, Rotterdam, Netherlands, 2016.

[10] L. Mata, I. Pedro, and F. Peixoto, "Parental support, student motivational orientation and achievement: the impact of emotions," International Journal of Emotional Education, vol. 10, no. 2, pp. 77-92, 2018.

[11] OECD, Beyond Academic Learning: First Results from the Survey of Social and Emotional Skills, OECD Publishing, Paris, France, 2021.

[12] C. Levinthal, E. Kuusisto, and K. Tirri, "How Finnish and Portuguese parents' implicit beliefs actualize at home," Frontiers in Education, vol. 6, pp. 1-15, 2021.

[13] D. Baumrind, "Current patterns of parental authority," Developmental Psychology Monograph, vol. 4, no. 1, pp. 1-103, 1971.

[14] K. Haimovitz and C. S. Dweck, "Parents' views of failure predict children's fixed and growth intelligence mind-sets," Psychological Science, vol. 27, no. 6, pp. 859-869, 2016.

[15] E. A. Moorman and E. M. Pomerantz, "Ability mindsets influence the quality of mothers' involvement in children's learning: an experimental investigation," Developmental Psychology, vol. 46, no. 5, pp. 1354-1362, 2010.

[16] G. Sykes and T. Bird, "Teacher education and the case idea," Review of Research in Education, vol. 18, no. 1, pp. 457-521, 1992.

[17] C. Spera, "A review of the relationship among parenting practices, parenting styles, and adolescent school achievement," Educational Psychology Review, vol. 17, no. 2, pp. 125-146, 2005.

[18] R. Sikiö, M. Siekkinen, L. Holopainen, G. Silinskas, M. Lerkkanen, and J. Nurmi, "Maternal parenting styles, homework help, and children's literacy development in language minority and Finnish-speaking families," European Journal of Psychology of Education, vol. 33, no. 2, pp. 235-250, 2017.

[19] L. Steinberg, S. D. Lamborn, S. M. Dornbusch, and N. Darling, "Impact of parenting practices on adolescent achievement: authoritative parenting, school involvement, and encouragement to succeed," Child Development, vol. 63, no. 5, pp. 1266-1281, 1992.

[20] J. Goodall and C. Montgomery, "Parental involvement to parental engagement: a continuum," Educational Review, vol. 66, no. 4, pp. 399-410, 2014.

[21] K. Sylva, E. Melhuish, I. Blatchford, and B. Taggart, The Effective Provision of Preschool Education (EPPE) Project: Technical Paper 12-the Final Report: Effective Pre-school Education, DfES/Institute of Education, University of London, London, UK, 2004.

[22] C. Levinthal and E. Kuusisto, "Parental engagement in children's learning: a holistic approach to teacher-parents' partnerships," in Pedagogy in Basic and Higher Education: Current Developments and Challenges, K. Tirri and A. Toom, Eds., pp. 203-219, IntechOpen, London, UK, 2020.

[23] C. Levinthal, E. Kuusisto, and K. Tirri, "Finnish and Portuguese parents' perspectives on the role of teachers in parentteacher partnerships and parental engagement," Education Sciences, vol. 11, no. 6, p. 306, 2021.

[24] L. Steinberg, "We know some things: parent-adolescent relationships in retrospect and prospect," Journal of Research on Adolescence, vol. 11, no. 1, pp. 1-19, 2001.

[25] G. Silinskas, N. Kiuru, K. Aunola, M.-K. Lerkkanen, and J.-E. Nurmi, "The developmental dynamics of children's academic performance and mothers' homework-related affect and practices," Developmental Psychology, vol. 51, no. 4, pp. 419-433, 2015.

[26] L. Justice, K. Purtell, D. Bleses, and S. Cho, "Parents' growth mindset and home-learning activities: a cross-cultural comparison of Danish and U.S. parents," Frontiers in Psychology, vol. 11, p. 1365, 2020.

[27] K. Muenks, D. B. Miele, G. B. Ramani, L. M. Stapleton, and M. L. Rowe, "Parental beliefs about the fixedness of ability," Journal of Applied Developmental Psychology, vol. 41, pp. 78-89, 2015.

[28] C. S. Dweck, Self-theories: Their Role in Motivation, Personality and Development, Psychology Press, New York, NY, USA, 2000.

[29] J. Epstein, School, Family and Community Partnerships-Preparing Educators and Improving Schools, Westview Press, Boulder, CO, USA, 2011.

[30] R. Deslandes and N. Rousseau, "Congruence between teachers' and parents' role construction and expectations about their involvement in homework," International Journal about Parents in Education, vol. 1, pp. 108-116, 2007.

[31] J. Goodall and J. Vorhaus, Review of Best Practices in Parental Engagement, Department of Education, London, UK, 2011.

[32] C. L. Green, J. M. T. Walker, K. V. Hoover-Dempsey, and H. M. Sandler, 'Parents' motivations for involvement in children's education: an empirical test of a theoretical model of parental involvement," Journal of Educational Psychology, vol. 99, no. 3, pp. 532-544, 2007.

[33] OECD, The Future of Education and Skills-Education 2030, OECD Publishing, Paris, France, 2018, https://www.oecd.org/ education/2030/E2030\%20Position\%20Paper\%20(05.04.2018). pdf.

[34] P. S. Braunschweig, C. Kappler, and E. Chiapparini, "No more homework? Negotiations of parental engagement in all-day schools," International Journal about Parents in Education, vol. 11, no. 1, pp. 46-54, 2019.

[35] A.-M. Kuusimäki, L. Uusitalo-Malmivaara, and K. Tirri, "Parents' and teachers' views on digital communication in Finland," Education Research International, vol. 2019, Article ID 8236786, 7 pages, 2019. 
[36] FNBE, National Core Curriculum for Basic Education 2014, Finnish National Board of Education Publications, Helsinki, Finland, 2016.

[37] K. Tirri, "The last 40 years in Finnish teacher education," Journal of Education for Teaching, vol. 40, pp. 1-10, 2014.

[38] M. L. Böök and S. Perälä-Littunen, "Responsibility in homeschool relations-Finnish parents' views," Children \& Society, vol. 29, no. 6, pp. 615-625, 2014.

[39] K. Tirri, E. Eisenschmidt, K. Poom-Valickis, and E. Kuusisto, "Current challenges in school leadership in Estonia and Finland: a multiple-case study among exemplary principals," Educational Research International, vol. 2021, Article ID 8855927, 11 pages, 2021.

[40] I. Alves, "Enacting education policy reform in Portugal-the process of change and the role of teacher education for inclusion," European Journal of Teacher Education, vol. 431, p. 64,82 .

[41] Eurydice/European Commission/EACEA, Teachers in Europe: Careers, Development and Well-Being; Eurydice Report, Publications Office of the European Union, Luxembourg, 2021, https:/eacea.ec.europa.eu/national-policies/ eurydice/content/teachers-europe-carreers-developmentand-well-being_en.

[42] T. Sarmento, "(Re)pensar a interacção escola-família [(Re) think the school-family interaction]," Revista Portuguesa de Educação, vol. 18, no. 1, pp. 53-75, 2005.

[43] A. R. R. Silva, L. M. Monico, L. Nobre-Lima, and M. J. Ferro, "Relações entre stress parental, tempo dispensado aos filhos e ajuda nos TPC [Relationships between parental stress, time dedicated to children and homework assistance]," International Journal of Developmental and Educational Psychology, vol. 1, no. 1, pp. 351-363, 2015.

[44] Presidência do Conselho de Ministros, Portugal, Decreto-lei [Decree-Law] No. 54. (2018, July 6). Diário da República no 129/2018, Série I (2918-2928), Presidência do Conselho de Ministros, Lisboa, Portugal, 2021, https://dre.pt/application/ conteudo/115652961.

[45] OECD, Curriculum Flexibility and Autonomy in Portugal-An OECD Review, OECD Publishing, Paris, France, 2018, http:// www.oecd.org/education/2030/Curriculum-Flexibility-andAutonomy-in-Portugal-an-OECD-Review.pdf.

[46] R. Legard, J. Keegan, and K. Ward, "In-depth interviews," in Qualitative Research Practice, J. Richie and J. Lewis, Eds., pp. 139-168, Sage, London, UK, 2013.

[47] U. H. Graneheim, B.-M. Lindgren, and B. Lundman, "Methodological challenges in qualitative content analysis: a discussion paper," Nurse Education Today, vol. 56, pp. 29-34, 2017.

[48] S. Elo and H. Kyngäs, "The qualitative content analysis process," Journal of Advanced Nursing, vol. 62, no. 1, pp. 107-115, 2008. 